\title{
How Much Time Do Adults Spend on Health-related Self-care? Results from the American Time Use Survey
}

\author{
Daniel E. Jonas, MD, MPH, Yoko Ibuka, PhD, and Louise B. Russell, PhD
}

Background: The amount of time individuals spend on health-related self-care is not known.

Objective: The aim of this study was to describe how much time American adults reported spending on health-related self-care (eg, taking insulin, dressing a wound).

Methods: We analyzed data from the first 5 years, 2003 to 2007 , of the population-based American Time Use Survey. of 64,310 respondents 25 years of age and older, 4267 reported 7022 episodes of health-related self-care on their survey day. We used descriptive statistics, weighted to represent US adults, to describe self-reported time and logit regressions to analyze the odds of engaging in self-care as a function of age, sex, race, and other characteristics. Because health status was collected only in 2006 to 2007, analyses were conducted separately for 2003 to 2007 and 2006 to 2007.

Results: Of Americans 25 years of age and older, 6.6\% engaged in health-related self-care each day. Among those reporting self-care, mean time reported was 90 minutes (median, 15 minutes); 20.6\% reported 2 hours or more. Regressions for 2006 to 2007 show that people aged 75 or older were 3.9 times as likely $(95 \% \mathrm{CI}, 2.7-5.8)$ to report self-care as persons aged 25 to 44 . Compared with persons in excellent health, those in fair health were 2.0 times as likely (95\% CI, 1.4-2.8) and those in poor health were 3.7 times as likely $(95 \% \mathrm{CI}, 2.5-5.6)$ to report engaging in self-care. Nonworking disabled persons reported self-care 4 times $(95 \% \mathrm{CI}, 3.1-5.3)$ as often as employed persons. Sex, race/ethnicity, presence of children, and body mass index were also significant.

Conclusions: Time spent on health-related self-care is disproportionately distributed across the population, with a larger amount of time reported by those in poor health ( 3.6 hours/week) and the nonworking disabled (3.2 hours/week). To provide patient-centered care and to promote optimal decisions about health-related time management when making recommendations for additional self-care tasks, clinicians need to talk to patients about how much time they are already spending on self-care.(J Am Board Fam Med 2011;24:380-390.)

Keywords: Adult, Patient Time, Self-Care, Time, Time Factors

Self-care, or self-management, is an integral part of the management of chronic diseases such as asthma, chronic obstructive pulmonary disease, heart failure,

This article was externally peer reviewed.

Submitted 2 November 2010; revised 17 March 2011; accepted 23 March 2011.

From the University of North Carolina, Chapel Hill, Department of Medicine (DEJ); Yale University, New Haven, CT Department of Epidemiology and Public Health (YI); and Rutgers, The State University of New Jersey, Newark Institute for Health, Health Care Policy and Aging Research (LBR).

Funding: none.

Conflict of interest: none declared.

Corresponding author: Daniel E. Jonas, University of North Carolina, Department of Medicine, Division of General Medicine, 5034 Old Clinic Building, CB \#7110, Old Clinic Building, CB \#, Chapel Hill, NC 27599 (E-mail: djonas@med.unc.edu). and diabetes. For some conditions, the majority of care is implemented day to day by patients, with physicians offering intermittent instruction. ${ }^{1,2}$ Appropriate selfcare can require considerable time and likely varies by condition and severity. For example, adult patients with cystic fibrosis devote almost 2 hours daily to self-care, ${ }^{3}$ and estimates suggest that recommended diabetes selfcare requires more than 2 hours daily. ${ }^{4}$

Self-care has been defined as "the personal and medical care performed by the patient, usually in collaboration with and after instruction by a health care professional." ${ }^{5}$ The time required for self-care (eg, taking insulin, dressing a wound) for most health conditions is not known, nor is the total time that individuals spend on self-care. Understanding 
the amount of time patients spend on self-care is important for several reasons. First, self-care is essential for optimal health. Second, the amount of time required for self-care tasks could be a very important factor in patient-centered decision making. Knowing what people currently choose to do seems an essential first step toward achieving optimal "health time" management. When patients have competing demands and only a set amount of time to devote to self-care, but there are hours of options, what should they prioritize? If time requirements are burdensome, clinicians may need to help patients set priorities to maximize health. Third, the time required may for some patients be a substantial barrier to compliance with self-care regimens. Several authors have explained that time requirements are barriers to self-care or health care more generally. ${ }^{3,6-9}$ One study found that more than $20 \%$ of patients identified "not enough time" as the biggest obstacle to effectively managing their diabetes. ${ }^{8}$

The American Time Use Survey (ATUS), from the US Bureau of Labor Statistics (BLS), is the first large-scale ongoing survey of time use in the United States. The ATUS interviews a nationally representative sample of noninstitutionalized adults about their activities during a 24-hour period. Detailed activity codes make it possible to identify time spent on personal health-related self-care for existing conditions, which is coded separately from time spent on primary prevention activities like physical activity. The purpose of this article is to describe the time American adults 25 years of age and older spend on health-related self-care using data from the survey's first 5 years (2003-2007).

\section{Methods}

\section{American Time Use Survey}

Conducted for the BLS by the Census Bureau, the ATUS began in January 2003. ${ }^{10}$ Households are selected from those that have completed their last interview for the Current Population Survey (CPS), the nation's monthly labor force survey. ${ }^{11}$ Thus, the ATUS, like the CPS, is based on a nationally representative sample of the civilian, noninstitutionalized US population. The process of selecting the ATUS sample begins by subsampling the CPS to reduce the oversample of less-populous states because accurate estimates by state, which are required for the CPS, are not necessary for the ATUS. Households are then stratified on race and
Hispanic origin, presence and age of children, and, for childless households, the number of adults; minority households and households with children are sampled at higher rates than other households. Finally, one respondent at least 15 years old is randomly selected from the members of each sample household. Approximately 40,000 households were selected in 2003 and approximately 26,000 per year from 2004 through 2007, with equal numbers selected each month throughout the year. Response rates ranged from $52.5 \%$ (2007) to $57.8 \%$ (2003). At our institutions, institutional review board approval was not necessary for this study because the de-identified data are publicly available.

Each monthly sample is divided into 4 parts, one for each week of the month. Within a week, $10 \%$ of the sample is assigned to each weekday and $25 \%$ to each weekend day. BLS weights adjust for the oversampling of weekend days as well as for stratification and nonresponse. ${ }^{11}$

The survey is conducted using computer-assisted telephone interviewing (see Appendix 1, available online at http://www.shepscenter.unc.edu/research_programs/ evidencebased_practice/publications/index.htm). Respondents are randomly assigned a day of the week and called the following day. During the interview, they are asked how they spent the 24 hours, beginning at $4 \mathrm{AM}$ the day before the call and ending $4 \mathrm{AM}$ the day of the call. For activities other than personal care, they are asked where they were and who was in the room or accompanied them. When respondents report 2 or more activities for the same time, they are asked to specify which was primary; except for childcare, interviewers do not ask about secondary activities. For respondents who are not reached on the first try, interviewers attempt subsequent contacts on the same day of the week for up to 8 consecutive weeks. Respondents in households that do not provide telephone numbers (5\% of the sample) are requested, by mail, to call the telephone center to complete the interview. Interviews with these respondents take place by telephone and cover the previous 24 hours, just as with other respondents. Respondents are interviewed only once; there is no longitudinal component.

ATUS's telephone interview is conducted as a conversation (see Appendix 1). Except for 12 common activities listed on the form, such as sleeping and eating/drinking, activities are not coded during the interview but are entered in the respondent's own words. The interviewer "walks" the respon- 
dent through his or her day, essentially asking, "...and what did you do next?" The coding of activities takes place only after the interview is finished. The interview asks about the day before the interview and has no longitudinal component, with one exception: a summary question about time spent away from home for 2 or more nights during the previous month.

After the interview is complete, 2 other interviewers/coders, working separately, assign codes to the activities reported. Each activity is assigned a 6-digit code. The first 2 digits indicate one of 17 major activity categories, the second 2 digits indicate an intermediate category, and the final 2 digits indicate the specific activity. ${ }^{12} \mathrm{We}$ report data for health-related self care (code 010301), which is under "personal care," ${ }^{01}$ subcategory health-related self-care. ${ }^{03}$ Health-related self-care also includes a separate code for "self-care, not elsewhere classified" (010399), a specific activity that only includes "feeling sick." We omitted this category because we were interested only in active self-care. Examples of personal health-related self-care are provided in Table 1.

The definition of health-related self care in the ATUS seems to be conservative (see Appendix 1). As noted, what is categorized as health-related selfcare is determined after the interview by 2 coders who did not conduct the interview. Routine selfcare, like toothbrushing or food preparation, is explicitly described by other codes. Exercise is included under health-related self-care only if done for medical reasons; otherwise it is coded under major category 13 ("sports, exercise, and recreation"), which includes exercise for leisure or for primary prevention. Health-related self-care secondary to another activity is noted if mentioned by the respondent but is not coded.

Demographic and other characteristics of respondents came from the ATUS survey and from the CPS. Neither the 2003 to 2005 ATUS nor the CPS asked about health conditions, but, in 2006 and 2007, the ATUS asked respondents their self-rated health, height, and weight as part of an Eating and Health module added by the Department of Agriculture.

\section{Data Analysis}

To focus on adults, and to avoid problems with predictors like education, which do not represent socioeconomic status well for adolescents and young adults, we omitted respondents younger
Table 1. Examples of Personal Health-related Self-care (code 010301)

Doing childbirth exercises

Dressing a wound

Taking vitamins

Resting because of injury

Giving oneself a shot

Taking insulin

Putting ice on injury

Gargling for sore throat

Resting because of illness

Taking medicine

Doing stress management exercises

Meditating (not religious)

Taking cough drops

Bandaging ankle

Giving oneself an injection

Testing blood sugar level

Applying ointment

Changing oxygen

Exercising or therapy for medical reasons

The above items exclude health-related self-care, not elsewhere classified, code 010399, because the only activity example is "feeling sick."

Source: American Time Use Survey Activity Lexicon: with activity examples-2003 (and the lexicons for 2004, 2005, and 2006). Washington, DC: Bureau of Labor Statistics. Available at: http://www.bls.gov/tus/lexicons.htm. Accessed 6 February 2009.

than age 25. We used the weights BLS provides for combining survey years to adjust for oversampling in some subpopulations, days of the week, and nonresponse to make national estimates. ${ }^{13}$ Unless stated, numbers are weighted.

Our initial analysis focused on descriptive statistics. We compared the full ATUS sample 25 years of age or older with respondents who reported health-related self-care for 2003 to 2007; the 2006 to 2007 sample was compared separately because these were the years when self-rated health and body mass index (BMI) were available. To explore the factors related to whether patients reported time on health-related self-care, we ran multivariable logistic regressions using a binary dependent variable (any time vs no time spent). We included the following predictors: age; sex; race/ethnicity (white non-Hispanic, black, Hispanic, other); education; employment status; household income; marital status; and presence of children. We repeated the analysis for 2006 to 2007 with the same predictors, plus BMI and self-rated health, which were only available for those years. We conducted ad- 
ditional multivariable logistic regressions stratified by age group (ages 25-44, 45-64, 65-74, and 75+; see Appendix 2, available online at http://www.shepscenter. unc.edu/research_programs/evidencebased_practice/ publications/index.htm).

Reported time for health-related self-care, in minutes per day, was described by means, medians, and ranges. The ATUS sample weights adjusted for stratification and nonresponse so that time estimates represent the national population of adults. The ATUS's successive difference replicate weights were used to obtain standard errors that adjust for the complex survey design.

We calculated yearly time for the average adult, and the average member of subgroups, eg, those with poor self-rated health, by multiplying mean daily time for the group (proportion who reported self-care time multiplied by mean time spent by those who reported time) by 365 days. We calculated weekly time by multiplying daily time by 7 . Although any one individual's self-care time varies from day to day, these extrapolations of daily time are valid because respondents who report self care on their interview day but do not engage in it on other days are balanced by respondents who do not report self-care on their interview day but do engage in it on other days. The proportions of participants who do and do not report self care on their interview days, and the times they report, are representative of the adult population. The ATUS thus provides an accurate snapshot of time spent by the average adult each day and can legitimately be extrapolated to a week or a year.

Analyses were conducted using SAS software version 9.1.3 (SAS Institute Inc., Cary, NC) or Stata software, version 11 (StataCorp, College Station, TX). Stata 11's survey procedures were used to adjust for complex sample design using successive difference replicate weights provided by BLS.

\section{Results}

Over the survey years 2003 to 2007 there were 64,310 ATUS respondents aged 25 years or older (Table 2). Of these, 4267 reported time for 7022 episodes of health-related self-care. Compared with all respondents, those reporting self-care were more likely to be older than 75 years $(23.2 \%$ vs $8.9 \% ; P<.001)$; women $(67.1 \%$ vs $57.2 \% ; P<$ $.001)$; childless (79.2\% vs $55.2 \% ; P<.001)$; retired (41.6\% vs $19.0 \% ; P<.001)$; not in the labor force/disabled (21.6\% vs 5.0\%; $P<0.001)$; or have annual household incomes less than $\$ 15,000$ (27.4\% vs $11.8 \% ; P<.001)$. Respondents reporting self-care in 2006 to 2007 were similar to those reporting self-care for 2003 to 2007.

Table 3 shows numbers weighted to represent the population of US adults. Overall, $6.6 \%$ of American adults 25 years of age or older reported spending time on health-related self-care each day during the years 2003 to 2007 ; $6.4 \%$ reported time spent on health-related self-care during the 2 years for which health data were available (2006 to 2007). More than $17 \%$ of persons aged 75 and older reported self-care time compared with $12 \%$ of those aged 65 to 74 years, $7 \%$ of those 45 to 64 years, and $3 \%$ of those 25 to 44 years. More than $27 \%$ of those in poor health reported self-care time compared with $3 \%$ to $6 \%$ for those in good to excellent health. When respondents reported 2 or more activities for the same time (ie, multitasking), only self-care activities designated as primary by the respondent are coded by the ATUS.

In multivariable logistic regression for the full 2003 to 2007 sample, age, sex, race/ethnicity, education, children, employment status, and income all influenced the odds of spending any time on selfcare (Table 4). Age was particularly important, with participants in the older age groups being much more likely to report time on self-care. Nonworking disabled persons were more than 7 times as likely to report time spent on self-care.

When the sample was limited to 2006 to 2007 and self-rated health and BMI were included in the regression, those with fair self-rated health were twice as likely, and those with poor self-rated health were 3.7 times as likely, to spend time on self-care as those with excellent self-rated health (Table 4). Those with BMI $\geq 35$ were 1.7 times as likely to spend time on self-care as those with a BMI of 20 to 29.9. Income and education were no longer significant.

In multivariable logistic regressions stratified by age group (Appendix 2), BMI was statistically significant for people aged 45 to 64 years and 65 to 74 years, but not for the youngest and oldest groups. There were other minor differences across age groups; for example, the sex difference seemed to be greater among persons 25 to 44 years of age than those in the older groups. The finding that fair or poor health increases the probability that a person will report health-related self-care is consistent 
Table 2. American Time Use Survey (ATUS) Sample 2003 to 2007 and Respondents Who Reported Health-related Self-care, 2003 to 2007 and 2006 to 2007, by Selected Characteristics

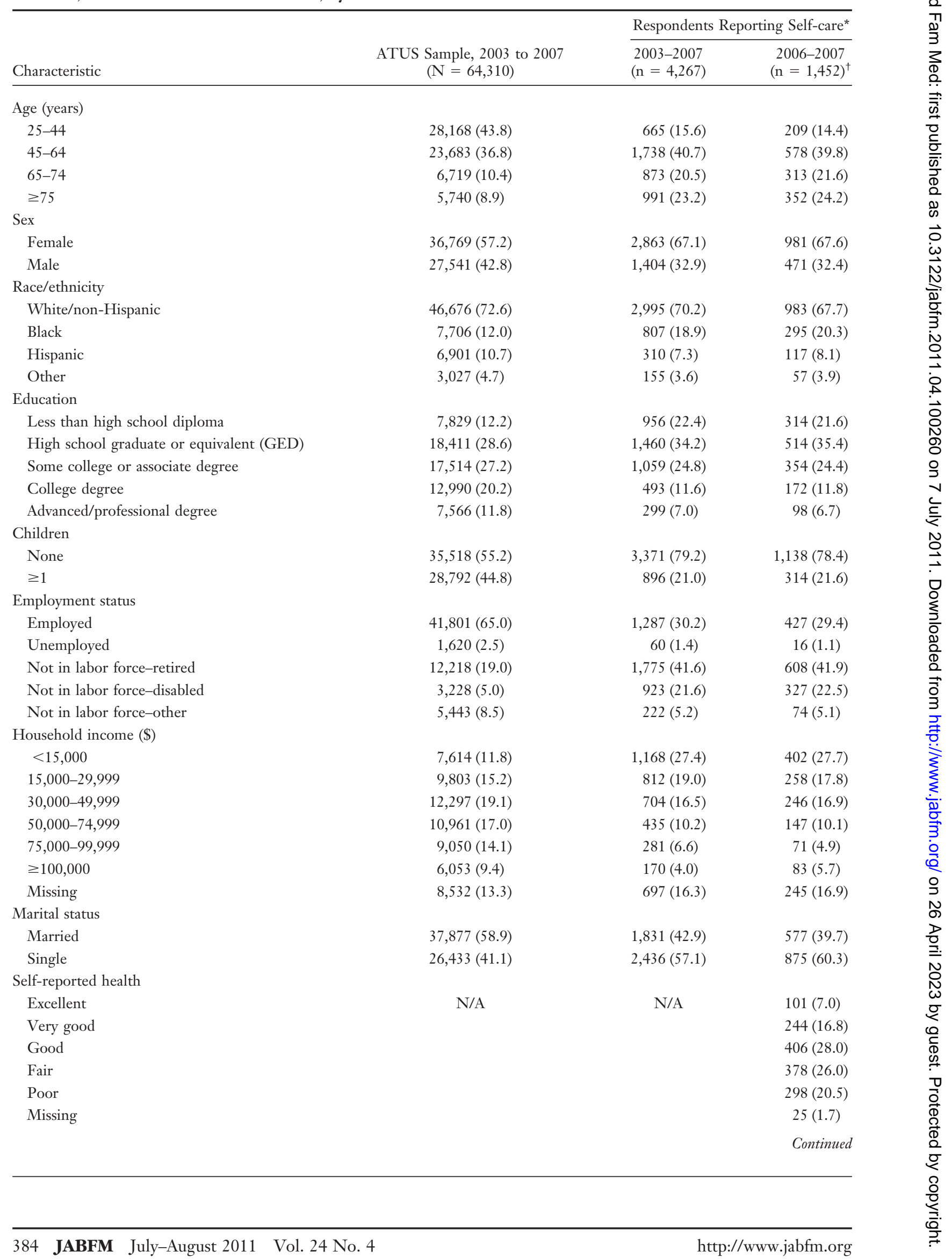




\begin{tabular}{|c|c|c|c|}
\hline \multirow[b]{2}{*}{ Characteristic } & \multirow[b]{2}{*}{$\begin{array}{l}\text { ATUS Sample, } 2003 \text { to } 2007 \\
(\mathrm{~N}=64,310)\end{array}$} & \multicolumn{2}{|c|}{ Respondents Reporting Self-care* } \\
\hline & & $\begin{array}{l}2003-2007 \\
(\mathrm{n}=4,267)\end{array}$ & $\begin{array}{l}2006-2007 \\
(\mathrm{n}=1,452)^{\dagger}\end{array}$ \\
\hline \multicolumn{4}{|c|}{ Body mass index } \\
\hline$<20$ & N/A & N/A & $44(3.0)$ \\
\hline $20-29.9$ & & & $808(55.6)$ \\
\hline $30-34.9$ & & & $274(18.9)$ \\
\hline$\geq 35$ & & & $254(17.5)$ \\
\hline Missing & & & $72(5.0)$ \\
\hline
\end{tabular}

Values presented as unweighted $\mathrm{n}(\%)$. Percentages may not total to 100 because of rounding. N/A indicates data not available because self-reported health and body mass index were only collected in 2006 and 2007.

*When respondents reported 2 or more activities for the same time (ie, multi-tasking), only self-care activities designated as primary by the respondent are included by the ATUS.

${ }^{\dagger}$ Excludes 5 respondents who reported self-care time but did not answer the eating and health module.

across age groups: the odds ratios are all approximately 2.0 for fair health; for poor health the odds ratios range from 3.5 to 4.2 .

Table 3. Percent of US Population 25 Years and Older Who Reported Spending Time on Health-Related Self Care by Selected Characteristics, 2003 to 2007 and 2006 to 2007

\begin{tabular}{lcc}
\hline Characteristic & 2003-2007 & 2006-2007* \\
\hline Overall & 6.6 & 6.4 \\
By age (years) & & \\
$25-44$ & 2.6 & 2.4 \\
$45-64$ & 7.2 & 7.1 \\
$65-74$ & 12.2 & 11.7 \\
$\geq 75$ & 17.3 & 17.1 \\
By self-rated health & & \\
Excellent & N/A & 2.9 \\
Very good & N/A & 3.5 \\
Good & N/A & 6.2 \\
Fair & N/A & 11.5 \\
Poor & N/A & 27.5 \\
Missing & N/A & 8.2 \\
By body mass index & & \\
$<20$ & N/A & 3.9 \\
$20-29.9$ & N/A & 5.6 \\
$30-34.9$ & N/A & 7.3 \\
$\geq 35$ & N/A & 12.4 \\
Missing & N/A & 5.4 \\
\hline
\end{tabular}

Weighted to represent the US civilian noninstitutionalized population aged 25 years and older. N/A indicated data not available because self-reported health and body mass index were only collected in 2006 and 2007. When respondents reported 2 or more activities for the same time (ie, multi-tasking), only selfcare activities designated as primary by the respondent are included by the American Time Use Survey.

*Excludes 67 respondents who did not answer the eating and health module; 5 reported health-related self care.
Among those reporting self-care, the mean time reported was 90 minutes. Half spent 15 minutes or less (the median), although $20.6 \%$ spent 120 minutes or more (Figure 1). Most people (65.8\%) reported one episode of self-care, but approximately a third reported 2 or more episodes. More episodes occurred in the morning between $6 \mathrm{AM}$ and 11:59 $\mathrm{AM}$ than in any other 6-hour period (39.7\% of episodes).

Average weekly time for the entire adult population, those who reported self care and those who did not, was 42 minutes per person, equivalent to 36.2 hours per year (95\% CI, 32.8-39.6). Multiplying hours per person by the 2005 population aged 25 years or older, adults spent an estimated 132 million hours on self-care per week, or 6.9 billion hours each year (more than 172 million 40-hour workweeks).

People with poor health who reported time for self-care spent a mean 113 minutes daily, and those who were disabled/not in the labor force reported 99 minutes daily. Averaging over those who reported time and those who did not, people with poor self-rated health spent a mean 3.6 hours per person per week (189 hours annually) on healthrelated self-care. People who were disabled/not in the labor force averaged 3.2 hours/week (169 hours annually), and those 75 years of age and older averaged 1.3 hours/week (69 hours/year).

\section{Discussion}

US adults spend a significant amount of time on health-related self-care activities: 42 minutes per week for the average adult and more than 3 hours per week for the average person with poor self- 
Table 4. Odds of Engaging in Health-related Self-care from Multivariate Logistic Regression

\begin{tabular}{|c|c|c|}
\hline Characteristic & $2003-2007$ & 2006-2007* \\
\hline \multicolumn{3}{|l|}{ Age (years) } \\
\hline $25-44$ & Ref & Ref \\
\hline $45-64$ & $2.0(1.7-2.3)$ & $2.0(1.6-2.6)$ \\
\hline $65-74$ & $2.4(2.0-2.9)$ & $2.8(2.0-3.8)$ \\
\hline$\geq 75$ & $3.2(2.6-3.9)$ & $3.9(2.7-5.8)$ \\
\hline \multicolumn{3}{|l|}{ Sex } \\
\hline Female & Ref & Ref \\
\hline Male & $0.74(0.67-0.82)$ & $0.75(0.64-0.88)$ \\
\hline \multicolumn{3}{|l|}{ Race/ethnicity } \\
\hline White, non-Hispanic & Ref & Ref \\
\hline Black & $1.2(1.1-1.4)$ & $1.2(0.99-1.5)$ \\
\hline Hispanic & $0.64(0.54-0.77)$ & $0.55(0.40-0.75)$ \\
\hline Other race & $1.0(0.81-1.3)$ & $1.1(0.73-1.7)$ \\
\hline \multicolumn{3}{|l|}{ Education } \\
\hline Less than high school diploma & Ref & Ref \\
\hline High school graduate or equivalent & $0.93(0.82-1.0)$ & $1.0(0.83-1.3)$ \\
\hline Some college/associate degree & $0.90(0.79-1.0)$ & $1.1(0.88-1.4)$ \\
\hline College degree & $0.66(0.56-0.78)$ & $0.77(0.59-1.0)$ \\
\hline Advanced/professional degree & $0.69(0.58-0.83)$ & $0.81(0.56-1.2)$ \\
\hline \multicolumn{3}{|l|}{ Children } \\
\hline None & Ref & Ref \\
\hline$\geq 1$ & $0.77(0.69-0.86)$ & $0.72(0.58-0.90)$ \\
\hline \multicolumn{3}{|l|}{ Employment status } \\
\hline Employed & Ref & Ref \\
\hline Unemployed & $0.93(0.63-1.4)$ & $0.55(0.29-1.0)$ \\
\hline Not in labor force-retired & $2.1(1.9-2.5)$ & $1.6(1.2-2.0)$ \\
\hline Not in labor force-disabled & $7.2(6.2-8.4)$ & $4.0(3.1-5.3)$ \\
\hline Not in labor force-other & $1.5(1.2-1.8)$ & $1.6(1.2-2.1)$ \\
\hline \multicolumn{3}{|l|}{ Income } \\
\hline$<15,000$ & Ref & Ref \\
\hline $15,000-29,999$ & $0.85(0.74-0.98)$ & $0.83(0.65-1.1)$ \\
\hline $30,000-49,999$ & $0.85(0.73-0.99)$ & $1.1(0.87-1.4)$ \\
\hline $50,000-74,999$ & $0.76(0.64-0.91)$ & $0.91(0.68-1.2)$ \\
\hline $75,000-99,999$ & $0.77(0.62-0.96)$ & $1.1(0.69-1.6)$ \\
\hline$\geq 100,000$ & $0.68(0.53-0.86)$ & $0.94(0.64-1.4)$ \\
\hline Missing & $0.84(0.73-0.96)$ & $1.0(0.79-1.3)$ \\
\hline \multicolumn{3}{|l|}{ Marital status } \\
\hline Married & Ref & Ref \\
\hline Single & $1.0(0.93-1.1)$ & $1.0(0.88-1.2)$ \\
\hline \multicolumn{3}{|l|}{ Self-reported health } \\
\hline Excellent & N/A & Ref \\
\hline Very good & & $1.0(0.73-1.4)$ \\
\hline Good & & $1.5(1.1-2.1)$ \\
\hline Fair & & $2.0(1.4-2.8)$ \\
\hline Poor & & $3.7(2.5-5.6)$ \\
\hline \multirow[t]{2}{*}{ Missing } & & $1.7(0.90-3.21)$ \\
\hline & & Continued \\
\hline
\end{tabular}


Table 4. Continued

\begin{tabular}{|c|c|c|}
\hline Characteristic & 2003-2007 & $2006-2007^{*}$ \\
\hline \multicolumn{3}{|c|}{ Body mass index } \\
\hline$<20$ & N/A & $0.68(0.44-1.0)$ \\
\hline $20-29.9$ & & Ref \\
\hline $30-34.9$ & & $1.3(1.0-1.5)$ \\
\hline$\geq 35$ & & $1.7(1.4-2.2)$ \\
\hline Missing & & $0.98(0.67-1.4)$ \\
\hline
\end{tabular}

Values presented as odds ratio $(95 \% \mathrm{CI})$, weighted to represent the US civilian noninstitutionalized population aged 25 years and older. All independent variables were entered and tested simultaneously. Ref indicates reference group for the characteristic. N/A indicates data not available because self-reported health and body mass index were only collected in 2006 and 2007 . The independent variables included age, sex, race/ethnicity, education, employment status, household income, marital status, and presence of children for 2003 to 2007; for 2006 to 2007, the independent variables also included body mass index and self-rated health.

*Excludes 67 respondents who did not answer the eating and health module; 5 reported health-related self care.

rated health. Time spent on health-related self-care is disproportionately distributed across the population, with a small segment of the population accounting for a large proportion of the time. Not surprisingly, our results support the expectation that people who have health problems are more likely to spend time engaging in self-care. A much larger percentage of those 65 years of age and older spent time on health-related self-care on any given day, although the median time spent by those who spent time was lower than for younger age groups. That may seem surprising, but it is consistent with the idea that many are spending time on things as simple as taking pills, which is less common among younger people.

To implement patient-centered decision making, clinicians should consider the time required for self- care and talk to patients about time demands. Our data provide a rough estimate of how much time, on average, various patients spend (eg, 3.6 hours/week for those with poor health, 3.2 hours/week for people who are disabled/not in the labor force). Knowing the starting point for what people currently do seems an essential first step toward achieving optimal "health time" management. When weighing various options for self-care, it may be important to negotiate which tasks are most important to develop plans that are tailored to individual patients and set realistic goals for self-care activities in the time available for each patient. Some self-care regimens may be too time consuming or complex for many patients to undertake without multidisciplinary support. ${ }^{14}$ Consideration of patient knowledge, health belief models, and health literacy are also important for understanding

Figure 1. Screen shot of American Time Use Survey interview form.

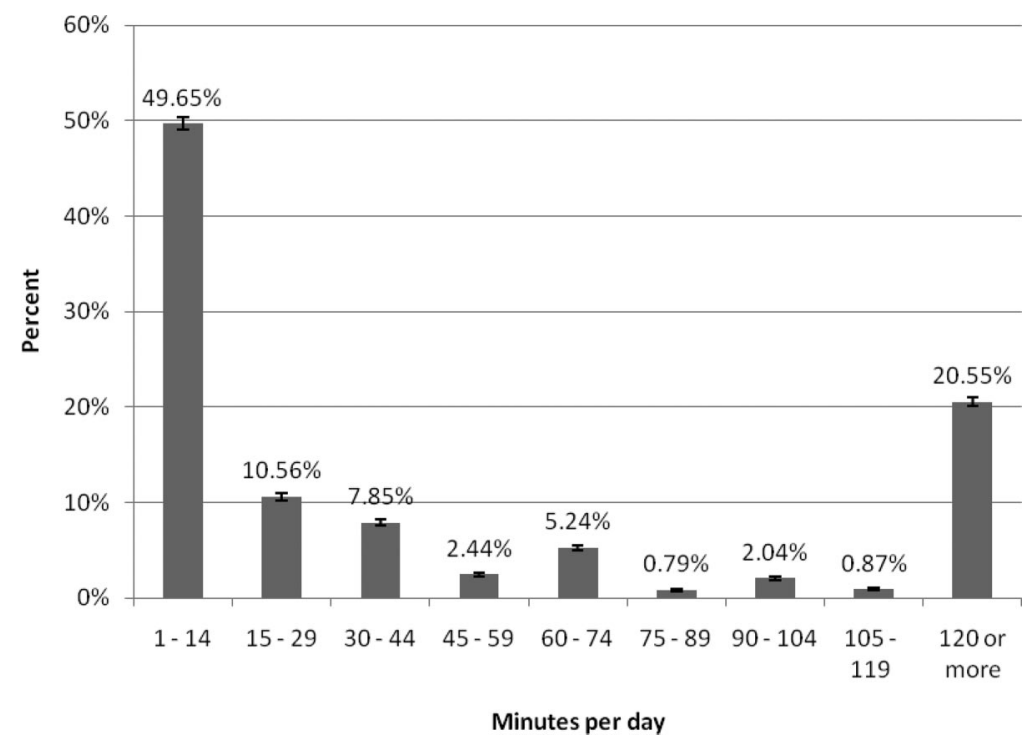


patients' capacity to maintain appropriate selfcare. $^{15,16}$

Although health outcomes may be improved with appropriate self-management, ${ }^{3,14,16-42}$ selfcare requirements may represent a substantial time investment for some conditions, leading patients to omit important tasks, depending on their time trade-off decisions. For example, a survey of diabetes patients found that $38 \%$ did not engage in recommended foot care or physical activity. ${ }^{8} \mathrm{Ap}$ proximately one fourth of adult cystic fibrosis patients report not completing recommended airway clearance, primarily because they are too busy, they forget, and because of the complexity of the regimen. ${ }^{3}$ Similar reasons for neglecting self-care have been reported among children with cystic fibrosis and asthma, ${ }^{43}$ as well as adults with diabetes, ${ }^{44}$ and suggest that time requirements may have an important impact on self-care. People's willingness to spend time likely depends on the perceived benefits of that self-care.

Since the emergence of the self-care movement in the 1970s, the health care system has shifted toward expecting chronically ill patients to play a more active role in their care, and time spent on self-care has likely increased. ${ }^{39}$ The self-care movement aims to increase patients' involvement in their own care, especially for chronic conditions, thereby fostering greater adherence to complex self-care regimens and improving outcomes. $1,39,45$

The ATUS data do not allow us to determine time spent on specific self-care activities or for specific health conditions. It is unclear how much of the time is dedicated to chronic disease selfmanagement (eg, taking insulin or foot care for diabetes), acute illness self-care (eg, gargling for a sore throat or icing an injury), or other purposes such as stress management. In addition, we cannot determine whether individuals with chronic diseases spend an optimal amount of time (ie, an amount that is appropriate, adequate, or effective) on self-care and whether the time should be reduced or increased. Nor can we assess time tradeoffs between alternative self-care activities. Nonetheless, the ATUS provides a useful starting point that helps clinicians understand how much time the average patient spends on health-related self-care, especially if that patient is in poor health.

Some would argue that self-care should be much more broadly defined to include general physical activity and cooking healthy foods, but our purpose here is to describe time spent on health-related selfcare without including activities for primary prevention, which we consider a separate issue from time that patients spend caring for existing health conditions. The time reported for physical activity has been described previously for the ATUS sample, ${ }^{46}$ with sports, exercise, and recreation reported by $17.6 \%$ of respondents (mean for those reporting any time spent, 114 minutes/day; mean for the average adult, including those who did and those who did not report time, 20 minutes/day).

Our study has several limitations. First, the ATUS relies on self-reported time rather than on direct observation of activities or completing a diary of activities as they occur, making the time estimates subject to recall bias. Second, ATUS response rates range from $52.5 \%$ (2007) to $57.8 \%$ (2003). Participants with the greatest self-care time requirements may be more likely to respond (eg, unemployed or retired individuals may be more likely to be at home to answer the phone) or less likely to respond (eg, disability or illness may make it difficult for individuals to answer the phone). In addition, the ATUS response is limited by (1) nonresponse from the CPS and (2) survey fatigue from the CPS; survey fatigue is a key reason why people refuse to participate in the ATUS. ${ }^{47}$ However, the CPS offers advantages in selecting the ATUS sample and adjusting for nonresponse because more is known about the base population. Third, time spent on health-related self-care as a secondary behavior (eg, while watching television) is not asked about, nor is it coded when volunteered (Appendix 1), making our estimates conservative. Fourth, we cannot determine time spent on specific self-care activities because the ATUS does not provide that level of detail; all health-related self-care activities are grouped under a single code. Finally, because the ATUS does not collect data on health conditions, we are unable to determine time spent on self-care by condition, such as diabetes or asthma, and therefore we cannot determine whether the amount of time spent is optimal.

\section{Conclusion}

Time spent on health-related self-care is disproportionately distributed across the population, with more time spent reported by those in poor health (mean, 3.6 hours/week) and the nonworking disabled (mean, 3.2 hours/week). To provide patient- 
centered care and to promote optimal decisions about health-related time management when making recommendations for additional self-care tasks, clinicians need to be aware of the time their patients are already spending on self-care. The ATUS provides benchmark data that can help clinicians identify those patients for whom the burden of self-care time is likely more substantial. Further research, including longitudinal studies of self-care time, is needed to understand the time required for self-care activities for specific health conditions.

\section{References}

1. Bodenheimer T, Lorig K, Holman H, Grumbach K. Patient self-management of chronic disease in primary care. JAMA 2002;288(19):2469-75.

2. Funnell MM, Anderson RM. MSJAMA: the problem with compliance in diabetes. JAMA 2000;284(13): 1709.

3. Sawicki GS, Sellers DE, Robinson WM. High treatment burden in adults with cystic fibrosis: challenges to disease self-management. J Cyst Fibros 2009;8(2): 91-6.

4. Russell LB, Suh DC, Safford MA. Time requirements for diabetes self-management: too much for many? J Fam Pract 2005;54(1):52-6.

5. Mosby. Mosby's Medical Dictionary, 8th ed. Selfcare. New York: Elsevier; 2008.

6. Aday LA. Economic and noneconomic barriers to the use of needed medical services. Med Care 1975; 13(6):447-56.

7. Lyman GH. Time is money for both the healthy and the sick. Med Care 2005;43(7):637-9.

8. Safford MM, Russell L, Suh DC, Roman S, Pogach L. How much time do patients with diabetes spend on self-care? J Am Board Fam Pract 2005;18(4): 262-70.

9. Stringer M. Personal costs associated with high-risk prenatal care attendance. J health Care Poor Underserved 1998;9(3):222-35.

10. US Department of Labor, Bureau of Labor Statistics. American Time Use Survey. 2005. Available at: http://www.bls.gov/tus/home.htm. Accessed $30 \mathrm{Au}-$ gust 2010.

11. US Department of Labor, Bureau of Labor Statistics. American Time Use Survey user's guide: understanding ATUS 2003 to 2007. 2009. Available at: http://www.bls.gov/tus/atususersguide.pdf. Accessed 30 August 2010.

12. US Department of Labor; Bureau of Labor Statistics. American Time Use Survey: activity coding lexicons. 2010. Available at: http://www.bls.gov/tus/ lexicons.htm. Accessed 30 August 2010.

13. Horrigan M, Herz D. Planning, designing, and executing the BLS American Time-Use Survey. Mon Labor Rev 2004;127(10):3-19.
14. Coffen RD, Dahlquist LM. Magnitude of type 1 diabetes self-management in youth: health care needs diabetes educators. Diabetes Educ 2009;35(2): 302-8.

15. DeWalt DA, Pignone MP. Reading is fundamental: the relationship between literacy and health. Arch Int Med 2005;165(17):1943-4.

16. Harvey JN, Lawson VL. The importance of health belief models in determining self-care behaviour in diabetes. Diabet Med 2009;26(1):5-13.

17. Ansell J, Jacobson A, Levy J, Voller H, Hasenkam JM. Guidelines for implementation of patient selftesting and patient self-management of oral anticoagulation. International consensus guidelines prepared by International Self-Monitoring Association for Oral Anticoagulation. Int J Cardiol 2005;99(1): $37-45$.

18. Bourbeau J, Nault D, Dang-Tan T. Self-management and behaviour modification in COPD. Patient Educ Couns 2004;52(3):271-7.

19. Carlson B, Riegel B, Moser DK. Self-care abilities of patients with heart failure. Heart Lung 2001;30(5): 351-9.

20. Damush TM, Weinberger M, Perkins SM, et al. The long-term effects of a self-management program for inner-city primary care patients with acute low back pain. Arch Int Med 2003;163(21):2632-8.

21. Effing T, Monninkhof EM, van der Valk PD, et al. Self-management education for patients with chronic obstructive pulmonary disease. Cochrane Database Syst Rev 2007(4):CD002990.

22. Fisher EB, Brownson CA, O'Toole ML, Anwuri VV, Shetty G. Perspectives on self-management from the Diabetes Initiative of the Robert Wood Johnson Foundation. Diabetes Educ 2007;33(Suppl 6):216S-24S.

23. Halpin HA, McMenamin SB, Pourat N, Yelin E. An analysis of California Assembly Bill 2185: mandating coverage of pediatric asthma self-management training and education. Health Serv Res 2006;41(3 Pt 2):1061-80.

24. Heisler M, Bouknight RR, Hayward RA, Smith DM, Kerr EA. The relative importance of physician communication, participatory decision making, and patient understanding in diabetes self-management. J Gen Int Med 2002;17(4):243-52.

25. Heneghan C, Alonso-Coello P, Garcia-Alamino JM, Perera R, Meats E, Glasziou P. Self-monitoring of oral anticoagulation: a systematic review and metaanalysis. Lancet 2006;367(9508):404-11.

26. Jordan JE, Briggs AM, Brand CA, Osborne RH. Enhancing patient engagement in chronic disease self-management support initiatives in Australia: the need for an integrated approach. Med J Aust 2008; 189(10 Suppl):S9-S13.

27. Lemmens KM, Nieboer AP, Huijsman R. A systematic review of integrated use of disease-management 
interventions in asthma and COPD. Resp Med 2009; 103(5):670-91.

28. Lorig KR, Holman H. Self-management education: history, definition, outcomes, and mechanisms. Ann Behav Med 2003;26(1):1-7.

29. Lorig KR, Sobel DS, Ritter PL, Laurent D, Hobbs M. Effect of a self-management program on patients with chronic disease. Eff Clin Pract 2001;4(6):256-62.

30. Lorig KR, Sobel DS, Stewart AL, et al. Evidence suggesting that a chronic disease self-management program can improve health status while reducing hospitalization: a randomized trial. Med Care 1999; 37(1):5-14.

31. Lowe J, Linjawi S, Mensch M, James K, Attia J. Flexible eating and flexible insulin dosing in patients with diabetes: results of an intensive self-management course. Diabetes Res Clin Pract 2008;80(3):439-43.

32. Monninkhof E, van der Aa M, van der Valk P, et al. A qualitative evaluation of a comprehensive selfmanagement programme for COPD patients: effectiveness from the patients' perspective. Patient Educ Couns 2004;55(2):177-84.

33. Newman S, Steed L, Mulligan K. Self-management interventions for chronic illness. Lancet 2004; 364(9444):1523-37.

34. Niesink A, Trappenburg JC, de Weert-van Oene GH, Lammers JW, Verheij TJ, Schrijvers AJ. Systematic review of the effects of chronic disease management on quality-of-life in people with chronic obstructive pulmonary disease. Resp Med 2007; 101(11):2233-9.

35. Norris SL, Engelgau MM, Narayan KM. Effectiveness of self-management training in type 2 diabetes: a systematic review of randomized controlled trials. Diabetes Care 2001;24(3):561-87.

36. Peytremann-Bridevaux I, Staeger P, Bridevaux PO, Ghali WA, Burnand B. Effectiveness of chronic obstructive pulmonary disease-management programs: systematic review and meta-analysis. Am J Med 2008;121(5):433-43.e4.

37. Sawicki GS, Sellers DE, McGuffie K, Robinson W. Adults with cystic fibrosis report important and un- met needs for disease information. J Cyst Fibros 2007;6(6):411-6.

38. Shaw EJ, Stokes T, Camosso-Stefinovic J, Baker R, Baker GA, Jacoby A. Self-management education for adults with epilepsy. Cochrane Database Syst Rev 2007(2):CD004723.

39. Shoor S, Lorig KR. Self-care and the doctor-patient relationship. Med Care 2002;40(4 Suppl):II40-4.

40. Stokes T, Shaw EJ, Camosso-Stefinovic J, Baker R, Baker GA, Jacoby A. Self-management education for children with epilepsy. Cochrane Database Syst Rev 2007(2): CD004724.

41. Wraight JM, Cowan JO, Flannery EM, Town GI, Taylor DR. Adherence to asthma self-management plans with inhaled corticosteroid and oral prednisone: a descriptive analysis. Respirology 2002;7(2): 133-9.

42. Wright SP, Walsh H, Ingley KM, et al. Uptake of self-management strategies in a heart failure management programme. Eur J Heart Fail 2003;5(3): 371-80.

43. Modi AC, Quittner AL. Barriers to treatment adherence for children with cystic fibrosis and asthma: what gets in the way? J Pediatr Psychol 2006;31(8): 846-58.

44. Mann DM, Ponieman D, Leventhal H, Halm EA. Predictors of adherence to diabetes medications: the role of disease and medication beliefs. J Behav Med 2009;32(3):278-84.

45. Coleman MT, Newton KS. Supporting self-management in patients with chronic illness. Am Fam Physician 2005;72(8):1503-10.

46. Russell LB, Ibuka Y, Abraham KG. Health-related activities in the American Time Use Survey. Med Care 2007;45(7):680-5.

47. Phipps PA, Vernon MK. Twenty-four hours: an overview of the recall diary method and data quality in the American Time Use Survey. In: Belli RF, Stafford FP, Alwin DF, eds. Calendar and Time Diary: Methods in Life Course Research. Thousand Oaks, CA: SAGE Publications, Inc; 2009:109-28. 